Received: 6 April 2017

Accepted: 29 August 2017

Published online: 21 September 2017

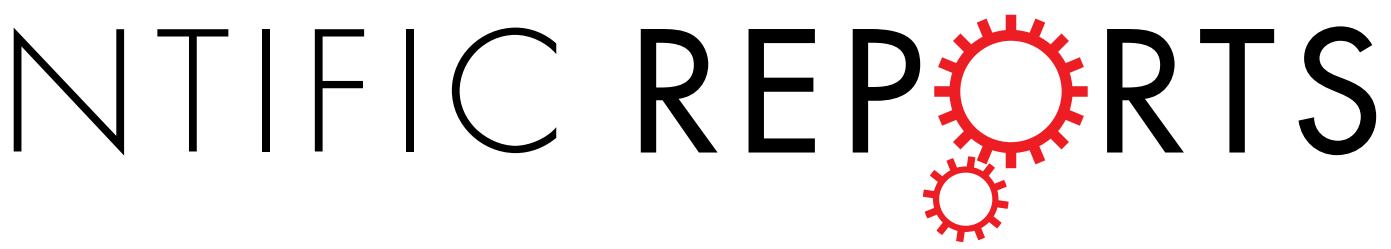

\title{
A brain-targeting lipidated peptide for neutralizing RNA-mediated toxicity in Polyglutamine Diseases
}

Qian Zhang1, Mengbi Yang2, Kasper K. Sørensen ${ }^{3}$, Charlotte S. Madsen ${ }^{3}$, Josephine T. Boesen ${ }^{3}$, Ying An ${ }^{1}$, Shao Hong Peng ${ }^{1}$, Yuming Wei ${ }^{1}$, Qianwen Wang ${ }^{2}$, Knud J. Jensen ${ }^{3}$, Zhong Zuo ${ }^{2}$, HoYin Edwin Chan ${ }^{1,4}$ \& Jacky Chi Ki Ngo ${ }^{1}$

Polyglutamine (PolyO) diseases are progressive neurodegenerative disorders caused by both proteinand RNA-mediated toxicities. We previously showed that a peptidyl inhibitor, P3, which binds directly to expanded CAG RNA can inhibit RNA-induced nucleolar stress and suppress RNA-induced neurotoxicity. Here we report a $\mathrm{N}$-acetylated and C-amidated derivative of P3, P3V8, that showed a more than 20 -fold increase in its affinity for expanded CAG RNA. The P3V8 peptide also more potently alleviated expanded RNA-induced cytotoxicity in vitro, and suppressed polyO neurodegeneration in Drosophila with no observed toxic effects. Further N-palmitoylation of P3V8 (L1P3V8) not only significantly improved its cellular uptake and stability, but also facilitated its systemic exposure and brain uptake in rats via intranasal administration. Our findings demonstrate that concomitant $\mathrm{N}$-acetylation, $\mathrm{C}$-amidation and palmitoylation of $\mathrm{P} 3$ significantly improve both its bioactivity and pharmacological profile. L1P3V8 possesses drug/lead-like properties that can be further developed into a lead inhibitor for the treatment of polyO diseases.

Polyglutamine (PolyQ) diseases, including Machado-Joseph Disease (MJD) and Huntington's disease, are a group of dominantly inherited progressive neurodegenerative diseases characterized by the existence of expanded CAG trinucleotide repeats within the coding region of disease genes ${ }^{1}$. Through transcription and translation, disease proteins carrying an extended polyQ stretch are detected in the affected tissues. It is widely accepted that polyQ disease toxicity is ascribed to the misfolding and aggregation of disease proteins ${ }^{2-4}$. However, an accumulation of evidence demonstrates that the expanded CAG-repeat RNA also contributes to toxicity in polyQ diseases ${ }^{5-8}$. Various expanded CAG RNA pathogenic pathways have recently been described, including the recruitment of muscleblind-like (MBNL) proteins to expanded CAG-repeat RNA foci ${ }^{9}{ }^{10}$, the generation of small CAG RNAs via Dicer cleavage $\mathrm{e}^{11,12}$, and the activation of nucleolar stress ${ }^{13,14}$.

We previously demonstrated that expanded CAG RNA triggers nucleolar stress and eventually induces toxicity both in vitro and in vivo ${ }^{13,14}$. Nucleolar stress is a cellular response to the failure in ribosome biogenesis and/or ribosome malfunction ${ }^{15}$. A reduction in ribosomal RNA ( $\left.r R N A\right)$ transcription causes an imbalance in the intracellular levels of ribosomal $R N A$ s and ribosomal proteins, which triggers ribosome assembly defects and eventually leads to nucleolar stress-induced apoptosis ${ }^{16,17}$. Our previous investigation showed that expanded CAG RNA physically interacts with the nucleolin (NCL) protein ${ }^{13}$, a multifunctional nucleolar protein that plays critical roles in precursor $r R N A$ (pre-rRNA) transcription ${ }^{18}$, processing ${ }^{19}$ and pre-ribosome assembly ${ }^{18,20}$. This RNA-protein interaction leads to upstream control element (UCE) hypermethylation and the down-regulation of $r R N A$ transcription, which induces nucleolar stress ${ }^{13}$. We developed a 13-amino acid peptide inhibitor, P3, which can inhibit NCL-expanded CAG RNA interaction and suppress RNA toxicity in polyQ diseases ${ }^{21}$. The P3 peptide was designed based on the structure of the RRM2 domain of $\mathrm{NCL}^{21}$ which contains the ribonucleoprotein domain-1 (RNP-1) motif ${ }^{22}$. Our study showed that P3 could directly and preferentially bind to expanded continuous CAG-repeat RNA in vitro ${ }^{21}$. This P3-CAG RNA interaction titrated endogenous NCL away from

${ }^{1}$ School of Life Sciences, The Chinese University of Hong Kong, Shatin, Hong Kong SAR, China. ${ }^{2}$ School of Pharmacy, The Chinese University of Hong Kong, Shatin, Hong Kong SAR, China. ${ }^{3}$ Department of Chemistry, University of Copenhagen, Thorvaldsensvej 40, 1871, Frederiksberg, Denmark. ${ }^{4}$ Gerald Choa Neuroscience Centre, The Chinese University of Hong Kong, Shatin, Hong Kong SAR, China. Mengbi Yang and Kasper K. Sørensen contributed equally to this work. Correspondence and requests for materials should be addressed to H.Y.E.C. (email: hyechan@cuhk. edu.hk) or J.C.K.N. (email: jackyngo@cuhk.edu.hk) 
binding to the toxic RNA and restored NCL- UCE interaction and pre-45s rRNA transcription ${ }^{21}$. Treatment of P3 suppressed expanded CAG RNA-induced cell death in a mammalian cell model and neurodegeneration in a Drosophila disease model ${ }^{21}$. The calculated maximal inhibitory concentration $\left(\mathrm{IC}_{50}\right)$ of P3 in inhibiting cell death was $4.369 \pm 1.140 \mu \mathrm{M}^{21}$. In this study, we engineered peptide P3 and identified a more potent inhibitor for targeting RNA toxicity in polyQ diseases.

\section{Results}

Alanine scanning of P3. P3 is derived from the primary structure of NCL ${ }^{21}$. We previously synthesized a series of $\mathrm{P} 3$ analogues, in which basic or aromatic residues were substituted with Ala and their binding to expanded $C A G$ RNA was measured to identify the amino acid side chains involved in the interaction with expanded CAG RNA. Our results showed that Lys3, Lys5, Tyr9, and Phe12 are indispensable and serve as the pharmacophores for RNA binding ${ }^{21}$. To further illustrate how the mutations affect the interaction between P3 and RNA, we performed isothermal titration calorimetry (ITC) experiments to characterize the interaction between each individual mutant (Supplementary Table S1) and expanded CAG RNA. All ITC experiments were performed using high ratios of peptide-to-RNA concentrations to increase the experiment's sensitivity. The heat generated by peptide dilution was determined by titrating the peptides into buffer only and was then subtracted from the binding titration curves of the corresponding peptides. The determined equilibrium dissociation constant $K_{D}$ of P3 is $\sim 8.4 \mu \mathrm{M}$ with both favorable enthalpy $(\Delta \mathrm{H}=-4.5 \mathrm{kcal} / \mathrm{mol})$ and entropy $(\mathrm{T} \Delta \mathrm{S}=2.4 \mathrm{kcal} / \mathrm{mol})$, suggesting that the peptide-RNA interaction is energetically driven by both favorable enthalpic and entropic components.

On the other hand, the determined equilibrium dissociation constant $K_{D}$ of P3MT3 and P3MT4 revealed that the mutations of the aromatic residues reduced the binding affinity to 16 and $17 \mu \mathrm{M}$ respectively, whereas mutations of the lysines (P3MT1, P3MT2 and P3MT5) had a more dramatic effect and reduced the affinity by 3-12 fold (Supplementary Table S1). In particular, the $\mathrm{K}_{\mathrm{D}}$ of P3MT2 and P3MT5 were increased to $100 \mu \mathrm{M}$ and $51 \mu \mathrm{M}$ respectively, indicating that among all the identified pharmacophores, Lys 5 and Lys 13 are most critical for RNA binding.

Amino acid substitutions of P3. The observation that favorable entropic change contributes to P3 interaction with expanded $C A G$ RNA suggests that the peptide may have undergone conformational changes upon binding to RNA. Structure prediction of the P3 peptide using the PEP-FOLD server ${ }^{23}$ suggested that although P3 does not adopt a well-defined tertiary structure, it may preferentially adopt a loosely folded coil conformation that positions the pharmacophores Lys3, Tyr9, and Phe12 on the same surface of the peptide, which may in turn facilitate the recognition and interaction of RNA (Supplementary Fig. S1). Such conformation is maintained partially by a network of interaction mediated by the side chain of Asp1. To test whether the orientation of Asp1 is important, we restricted it by substituting Gly2 with D-alanine (P3V1). Our result shows that the binding affinity of P3V1 was improved by 4 -fold which gave a $K_{D}$ of $2 \mu \mathrm{M}$. Such improvement could be due to better stabilization of the RNA-interacting surface via the restriction of Asp1 or because the replacement of Gly by D-Ala minimized the entropic loss upon binding by restricting the flexibility of the peptide. Analysis of the ITC results reveals that the change in the Gibbs free energy of P3V1 mainly originated from a favorable gain in enthalpy, indicating that the former scenario is more likely. Considering that both Phe12 and Lys13 are important for RNA binding, we kept the 13-mer P3 as our minimal construct for further studies.

To improve the binding affinity and specificity of P3 toward expanded CAG RNA, we performed amino acid substitutions at individual pharmacophores using natural amino acids with similar properties, i.e. Tyr and Phe to other aromatic side chains; Lys to Arg (Table 1). Substitution of Tyr9 with the larger Trp side chain (P3V2) resulted in a lower $\mathrm{K}_{\mathrm{D}}$ of $2.2 \mu \mathrm{M}$ and the substitution of Phe with less hydrophobic Tyr (P3V3) and Trp (P3V4) also improved the binding of peptide to expanded CAG RNA by nearly 2 - to 4 -fold, respectively. These results indicate that although alterations of the size or polarity of the aromatic residues improved the binding affinity of P3, only modest improvements were obtained. On the other hand, the $\mathrm{K}_{\mathrm{D}}$ value of P3V5, in which Lys3 and Lys5 both mutated to Arg residues, was approximately $0.86 \mu \mathrm{M}$, reflecting a nearly 10-fold improvement over the P3 peptide. Contrarily, when we mutated all three Lys to Arg (P3V6), the $K_{D}$ of the peptide increased to $23 \mu \mathrm{M}$, indicating that the replacement of the amine of Lys 13 with a guanidinium is not favored.

Termini modifications improve P3 activity. Next, we explored whether modifications at the $\mathrm{N}$ - and $\mathrm{C}$-termini could improve the binding and inhibitory activity of P3. N-terminal acetylation and C-terminal amidation neutralize the charges at both ends of the peptide and we speculated that it may increase its biological activity. The C-terminal amide was incorporated by solid-phase synthesis of the peptide on a Rink amide linker, while the $\mathrm{N}$-terminal modifications were introduced after assembly of the peptide and before acidolytic release of the completed structure. The $\mathrm{K}_{\mathrm{D}}$ value of P3V7 was determined to be $2 \mu \mathrm{M}$ using ITC, indicating that $\mathrm{C}$-terminal amidation improved the peptide affinity to expanded RNA. When the N-terminus was also acetylated, the dissociation constant of P3V8 was further lowered to $0.33 \mu \mathrm{M}$ (Table 1). Based on these observations, we further synthesized P3V9, which combined the modifications of P3V8 and P3V5 (N-acylation, C-amidation and Lys-to-Arg mutation) with the hope to further improving the binding affinity of the peptide. To our surprise, the binding affinity of the new peptide was not improved, as the $K_{D}$ value was $2.3 \mu \mathrm{M}$ (Table 1 ). We next investigated whether substitution of Lys3 and Lys5 with other non-natural Lys and Arg analogs would improve the activity of P3V8. The homologated Arg analog, homoarginine (hArg), and two shortened Lys analogs, ornithine (Orn) and 2,3-diaminopropionic acid (Dap), were used for substitution in our studies (Supplementary Table S2, P3 variants 14-19 respectively). Our results reveal that when either Lys3 or Lys5 was replaced by any of the amino acid analogs, no binding could be detected between the P3 variant and the expanded CAG RNA using ITC. This indicates that the chain length of Lys in P3V8 is crucial for its bioactivity. In addition, the linear dimer of P3V8, 


\begin{tabular}{|l|l|l|}
\hline Peptide & Sequence & $\mathbf{K}_{\mathbf{D}}(\boldsymbol{\mu M})$ \\
\hline P3WT & Asp-Gly-Lys-Ser-Lys-Gly-Ile-Ala-Tyr-Ile-Glu-Phe-Lys & $8.37 \pm 3.83$ \\
\hline $\begin{array}{l}\text { P3 variant } \\
\text { (P3V1) }\end{array}$ & Asp-\{d-Ala\}-Lys-Ser-Lys-Gly-Ile-Ala-Tyr-Ile-Glu-Phe-Lys & $2.00 \pm 0.34$ \\
\hline $\begin{array}{l}\text { P3 variant } \\
\text { (P3V2) }\end{array}$ & Asp-Gly-Lys-Ser-Lys-Gly-Ile-Ala-Trp-Ile-Glu-Phe-Lys & $2.21 \pm 1.27$ \\
\hline $\begin{array}{l}\text { P3 variant } \\
\text { 3 (P3V3) }\end{array}$ & Asp-Gly-Lys-Ser-Lys-Gly-Ile-Ala-Tyr-Ile-Glu-Tyr-Lys & $1.74 \pm 0.67$ \\
\hline $\begin{array}{l}\text { P3 variant } \\
\text { (P3V4) }\end{array}$ & Asp-Gly-Lys-Ser-Lys-Gly-Ile-Ala-Tyr-Ile-Glu-Trp-Lys & $4.44 \pm 0.47$ \\
\hline $\begin{array}{l}\text { P3 variant } \\
\text { (P3V5) }\end{array}$ & Asp-Gly-Arg-Ser-Arg-Gly-Ile-Ala-Tyr-Ile-Glu-Phe-Lys & $0.86 \pm 0.17$ \\
\hline $\begin{array}{l}\text { P3 variant } \\
\text { (P3V6) }\end{array}$ & Asp-Gly-Arg-Ser-Arg-Gly-Ile-Ala-Tyr-Ile-Glu-Phe-Arg & $23.78 \pm 2.78$ \\
\hline $\begin{array}{l}\text { P3 variant } \\
\text { (P3V7) }\end{array}$ & Asp-Gly-Lys-Ser-Lys-Gly-Ile-Ala-Tyr-Ile-Glu-Phe-Lys-NH 2 & $3.67 \pm 0.26$ \\
\hline $\begin{array}{l}\text { P3 variant } \\
\text { 8 (P3V8) }\end{array}$ & Ac-Asp-Gly-Lys-Ser-Lys-Gly-Ile-Ala-Tyr-Ile-Glu-Phe-Lys-NH ${ }_{2}$ & $0.33 \pm 0.04$ \\
\hline $\begin{array}{l}\text { P3 variant } \\
\text { 9 (P3V9) }\end{array}$ & Ac-Asp-Gly-Arg-Ser-Arg-Gly-Ile-Ala-Tyr-Ile-Glu-Phe-Lys-NH \\
\hline
\end{tabular}

Table 1. Binding affinity of P3V1-9 expanded $M J D_{C A G 78}$ RNA. P3WT or P3 variants $(0.7 \mathrm{mM})$ were titrated into $M J D_{C A G 78}$ RNA $(0.5 \mu \mathrm{M})$ and the thermal titration data were fitted to the 'one binding site model' to determine the dissociation constant $\left(\mathrm{K}_{\mathrm{D}}\right)$. WT indicates wild type. Data are expressed as mean \pm S.E.M. for at least 3 independent experiments.

which has two copies of the peptide in close vicinity, did not show any binding (Supplementary Table S2, P3V20 and P3V21). The abolishment of the bioactivity may be due to steric hindrance.

To test whether P3V8 specifically targets expanded CAG RNA, ITC experiments were performed using unexpanded $C A G$ RNA ( $M J D_{C A G 27}$ RNA), expanded $C A G$ RNA ( $M J D_{C A G 78}$ RNA), and expanded $C A A / G$ RNA $\left(M J D_{C A A / G 78} \mathrm{RNA}\right)$, respectively, to investigate whether the binding of P3V8 is RNA expansion-dependent and sequence-dependent (Supplementary Table S3). Our results demonstrate that P3V8 bound unexpanded RNA or expanded $C A A / G$ RNA with nearly 6-9-fold lower affinity, which indicates that P3V8 is expanded $C A G$ RNA-specific.

P3 derivatives showed improved suppressive effects on polyglutamine neurodegeneration in vivo. Given that P3V5 and P3V8 bind expanded CAG RNA with significantly higher affinities than P3, we next tested their inhibitory activities against polyQ neurodegeneration in vivo. We previously demonstrated that the full-length $M J D_{C A G}$ transgenic Drosophila model, $f M J D_{C A G 27 / 84}$, can be used to investigate the suppression effects of synthetic peptide inhibitors on both expanded RNA and polyQ protein toxicities ${ }^{21}$. Here we utilized the DsRed ${ }_{C A G 0 / 100}$ Drosophila model to investigate the suppressive effects of the P3 analogs on RNA toxicity. In this model, the CAG repeat is located in the $3^{\prime}$ untranslated region of the DsRed reporter gene ${ }^{7}$. The transcribed expanded CAG RNA is not translated into polyQ protein, and thus the toxicity is solely attributed to the expression of DsRed CAG100 RNA. In brief, the expression of expanded CAG RNA causes severe retinal degeneration in the animal that can be quantified by a pseudopupil assay ${ }^{7}$. Inhibitors that can suppress neurotoxicity will result in the recovery of the number of rhabdomeres within the ommatidium. To test our derivatives, third instar larvae were fed different amounts of peptide dissolved in sucrose solution for $2 \mathrm{hr}$ and then allowed to culture in standard fly food until the flies were 12 days old, at which time they were sacrificed for the pseudopupil assay. We observed that treatment with $50 \mu \mathrm{M}$ of P3 peptide moderately suppressed neurotoxicity in DsRed ${ }_{C A G 100}$ flies (pseudopupil score, $3.74 \pm 0.05$; Fig. 1a and b). In contrast, derivatives P3V5 and P3V8 both significantly suppressed neurotoxicity and recovered the number of rhabdomeres with much greater efficiency (Fig. 1c-f). In particular, P3V8 displayed a high level of potency against the neurotoxicity in $\operatorname{DsRed}_{C A G 100}$ flies and achieved a pseudopupil score of $4.32 \pm 0.25$ in comparison to P3V5's score of $3.64 \pm 0.22$ after $1 \mu \mathrm{M}$ treatment (Fig. $1 \mathrm{~d}$ and f). Based on the results from the ITC experiments and pseudopupil assay, the peptide derivative P3V8 seems to be the most potent P3 variant that exerts inhibitory activity against expanded CAG RNA-induced neurotoxicity.

P3V8 restored the expression level of pre-rRNA in a fly model expressing expanded CAG RNA. Ribosomal RNA ( $r R N A)$ synthesis occurs within the nucleolus ${ }^{15}$. We previously showed that expanded $C A G$ RNA induces nucleolar stress by preventing the nucleolar protein NCL from binding to the upstream control element of the $r R N A$ promoter, leading to the downregulation of $r R N A$ transcription ${ }^{13}$. To investigate whether P3V8 suppressed neurotoxicity by alleviating expanded CAG RNA-induced nucleolar stress in vivo, we measured the expression levels of pre-rRNA in DsRed ${ }_{C A G 100}$ flies treated with the peptide. Real-time PCR analysis showed that P3V8 could restore the transcript level of pre-rRNA in a dose-dependent manner. When DsRed ${ }_{C A G 100}$ flies were treated with $1 \mu \mathrm{M}$ of P3V8, the pre-rRNA level was fully recovered to the DsRed ${ }_{C A G O}$ control level (Fig. 2). This confirms that P3V8 subdued polyQ neurodegeneration in vivo by effective mitigation of the expanded $C A G$ RNA-induced nucleolar stress. 
(a)

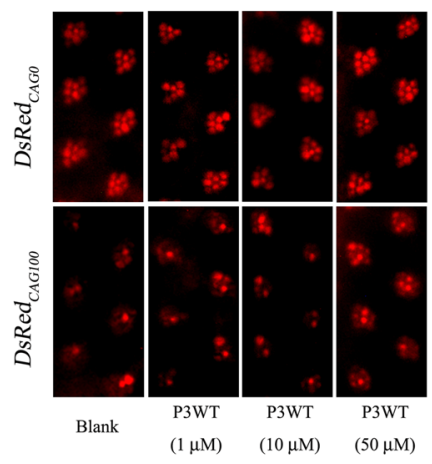

(c)

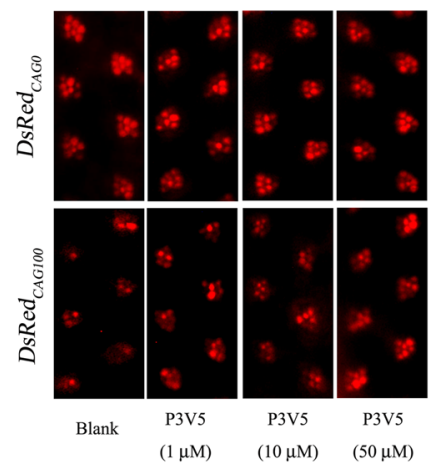

(e)

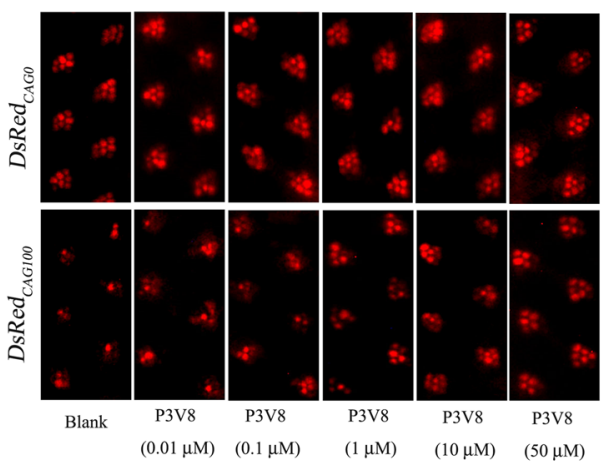

(b)

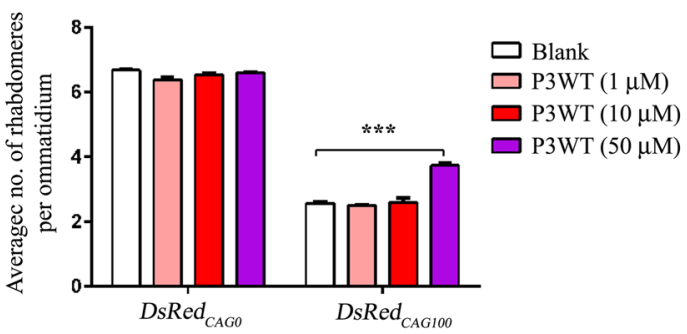

(d)

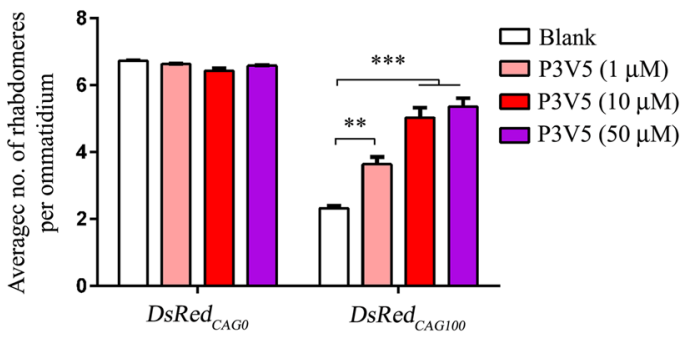

(f)

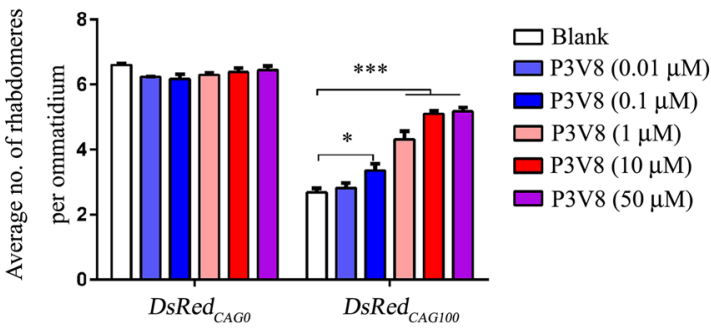

Figure 1. P3V8 most effectively suppresses expanded CAG RNA-induced RNA toxicity in vivo. (a) Effect of

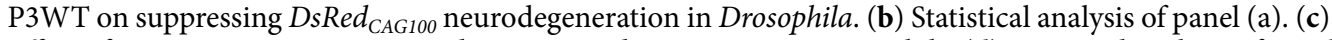

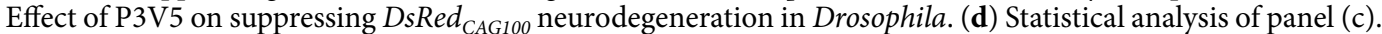
(e) Effect of P3V8 on suppressing DsRed ${ }_{C A G 100}$ neurodegeneration in Drosophila. (f) Statistical analysis of panel (e). Pseudopupil assay was performed on 12 day-old adult flies. The flies were of genotypes $w$; gmr-GAL4 UAS$\operatorname{DsRed}_{C A G O} /+;+/+$ and $w ; g m r-G A L 4 /+; U A S-D s R e d_{C A G 100} /+$. Data are expressed as mean \pm S.E.M. for at least 3 independent experiments. *Indicates $P<0.05$, **indicates $P<0.01$ and $* * *$ indicates $P<0.001$.

P3V8 suppressed expanded CAG RNA-induced cell death by modulating rRNA transcription in vitro. We next investigated whether $\mathrm{P} 3 \mathrm{~V} 8$ could also mitigate expanded $C A G \mathrm{RNA}$-induced toxicity in mammalian cells. Overexpression of $E G F P_{C A G 78}$ RNA in HEK293 cells has been shown to induce nucleolar stress and apoptosis ${ }^{21}$. To compare the inhibitory activity of P3WT and P3V8, we used the peptide transfection reagent DeliverX (DX) to deliver P3WT and P3V8 to EGFP ${ }_{C A G 78}$ RNA-expressing HEK293 cells. Figure 3a shows that irrespective of the addition of DX transfectant, treatment of P3WT lower than $1 \mu \mathrm{M}$ did not elicit any significant suppression effect on expanded CAG RNA-induced cell death. Although P3V8 alone did not exert any cellular effect, its administration with the aid of DX could effectively alleviate the cytotoxicity induced by expanded CAG RNA (Fig. 3b). To confirm that P3V8 inhibited expanded CAG RNA-mediated nucleolar stress, we measured the levels of pre-45s rRNA in EGFP ${ }_{C A G 78}$ RNA-expressing cells with or without treatment of P3V8 (Fig. 3c). Overexpression of the expanded CAG RNA reduced the level of pre-45s $r R N A$ to approximately $40 \%$ of the untransfected control. 


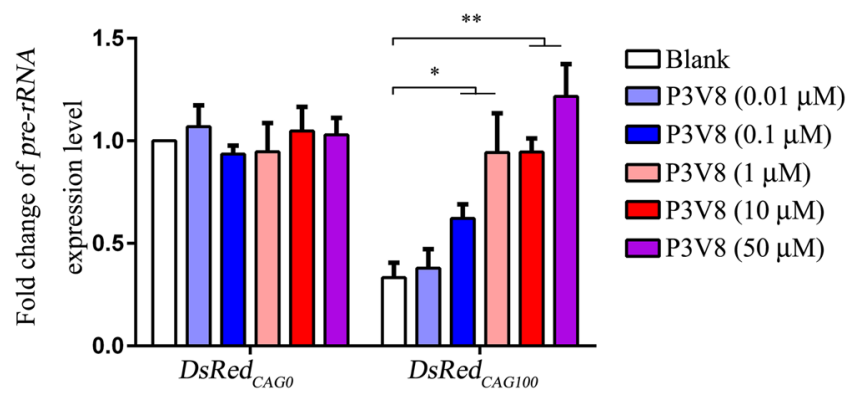

Figure 2. Treatment of P3V8 peptide suppresses nucleolar stress in vivo. Treatment of P3V8 restored pre$r R N A$ levels in $\operatorname{DsRed}_{C A G 100}$ flies. Real-time PCR was performed to determine the levels of pre-rRNA. Data are presented as fold change of the relative pre- $r R N A$ expression levels compared with the blank. Experiments were repeated at least 3 times, and data are expressed as mean \pm S.E.M. *Indicates $P<0.05$ and $* *$ indicates $P<0.01$.

(a)

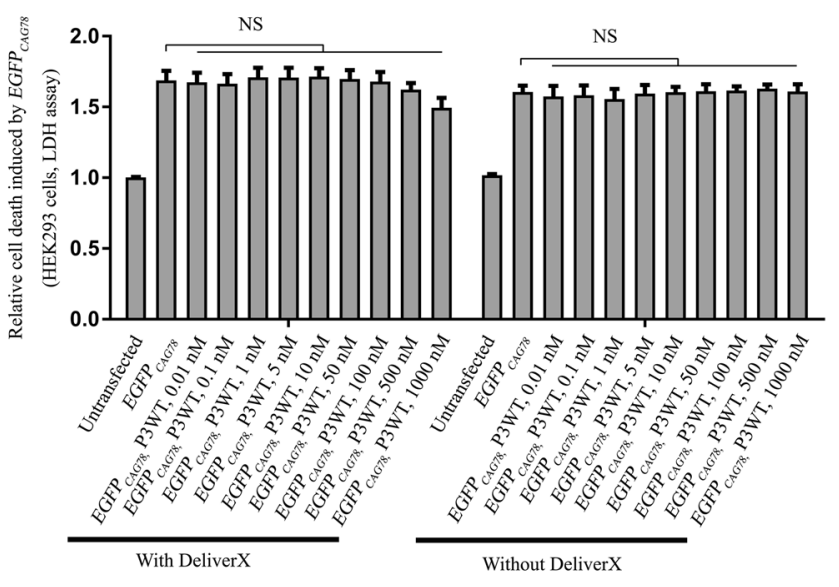

(b)

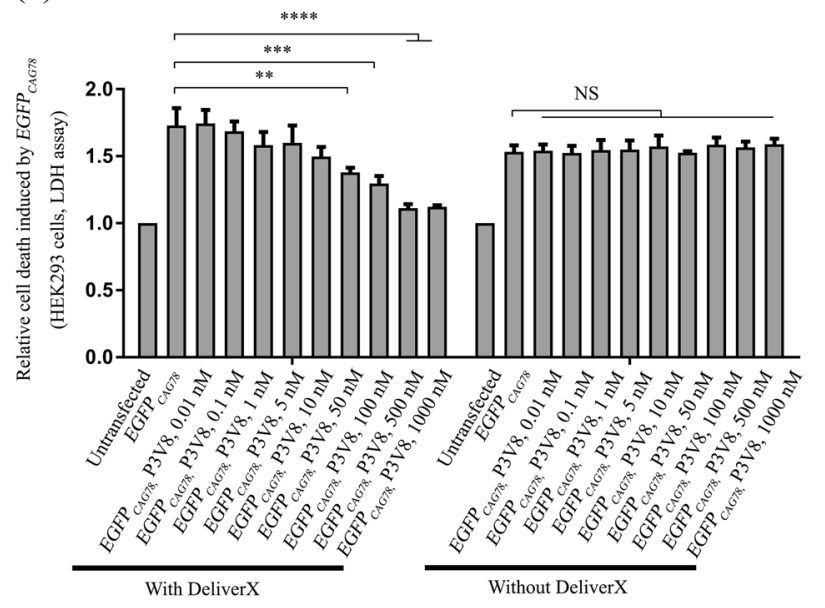

(c)

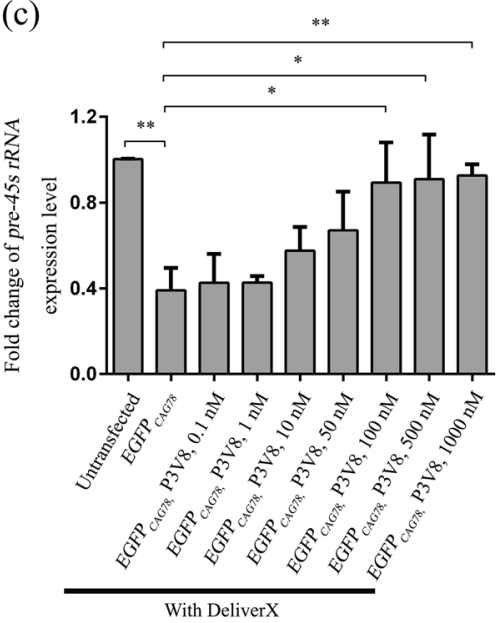

Figure 3. P3V8 effectively inhibits cytotoxicity induced by expanded CAG RNA in vitro. (a) Dose-dependent effect of synthetic P3WT in the absence or presence of DeliverX on the inhibition of cell death in EGFP ${ }_{C A G 78}$ RNA-expressing HEK293 cells. (b) Dose-dependent effect of synthetic P3V8 in the absence or presence of

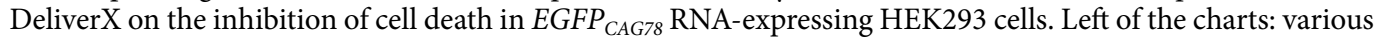
amount of P3WT (a) or P3V8 (b) were transfected into individual culture wells by DeliverX $4 \mathrm{hr}$ after plasmid transfection. Right of the charts: P3WT (a) or P3V8 (b) was added into individual culture wells immediately after plasmid transfection. A lactate dehydrogenase (LDH) cytotoxicity assay was performed. (c) Treatment of P3V8 (with DeliverX) restored pre-45s rRNA levels in EGFP ${ }_{C A G 78}$ RNA-expressing HEK293 cells. Cells were transfected with various amount of P3V8 using DeliverX. Data are presented as fold change of the relative pre45s rRNA expression levels compared with the untransfected samples. Experiments were repeated at least 3 times and data are expressed as mean \pm S.E.M. NS indicates no significance. *Indicates $P<0.05$, **indicates $P<0.01, * * *$ indicates $P<0.001$ and $* * * *$ indicates $P<0.0001$. 
Upon P3V8 treatment, a dose-dependent restoration of pre-45s $r R N A$ level was observed (Fig. 3c). Taken together, our results demonstrate that P3V8 could effectively mitigate expanded CAG RNA-induced nucleolar stress and neutralize the cytotoxic effect.

Assessment of P3V8 toxicity. Because we aim to develop P3V8 into a potent inhibitor that targets RNA toxicity in degenerating cells within the nervous system, we assessed whether P3V8 had deleterious effects on neuronal cells by determining lactate dehydrogenase release in the culturing medium of rat cortical neurons. After incubation of P3V8 in concentrations ranging from $0.01 \mathrm{nM}$ to $1 \mu \mathrm{M}$ for $72 \mathrm{hr}$, no significant cell death was observed in the P3V8-treated neurons when compared to the untreated control (Supplementary Fig. S2). It should be noted that the peptide also did not show any observable effect when DsRed ${ }_{C A G 0}$ Drosophila was treated with P3V8 at up to $50 \mu \mathrm{M}$ (Fig. 1e and f). This indicates that P3V8 exhibits low cytotoxicity both in vitro and in vivo.

N-terminally acylated P3V8 showed enhanced cellular uptake. Acylation of peptides with long-chain lipids has been shown to improve their cellular uptake, in vivo half-life, and membrane permeability and to change their pharmacokinetic properties ${ }^{24-26}$. Importantly, lipid solubility is a key factor for the transportation of inhibitors across the blood-brain barrier. We therefore investigated whether acylation of P3V8 could improve its cellular uptake in vitro as well as bioavailability both in vitro and in vivo. The L1P3V8 peptide was generated by introducing palmitic acid $\mathrm{N}$-terminally to P3V8 in place of $\mathrm{N}$-acetylation (Fig. 4a). LC/MS was used to detect the level of P3V8 or L1P3V8 uptaken by HEK293 cells after $3 \mathrm{hr}$ treatment. Figure $4 \mathrm{~b}$ shows that higher cellular concentration of L1P3V8 was measured in HEK293 cells when compared to that of P3V8 in both $500 \mathrm{nM}$ and $1 \mu \mathrm{M}$ treatment groups. While we could detect a low cellular concentration of L1P3V8 in HEK293 cells treated with $100 \mathrm{nM}$ of peptide, no uptake of P3V8 was detected (Fig. 4b). These data collectively demonstrated that the lipidation of P3V8 improved peptide cellular uptake. We next administered L1P3V8 to EGFP ${ }_{C A G 78}$ RNA-expressing HEK293 cells without any DX peptide transfecting reagents to determine whether lipidation can facilitate the cellular uptake of the peptide. As shown in Fig. 4c, L1P3V8 alone effectively inhibited expanded CAG RNA-induced cell death with an empirical $\mathrm{IC}_{50}$ value of $\sim 100 \mathrm{nM}$. In addition, L1P3V8 showed no cytotoxic effects on rat cortical neurons and DsRed ${ }_{C A G O}$ Drosophila model, and no obvious alteration in egg-to-adult viability of wild type flies (Supplementary Figs S3 and S4 and Fig. 4d). Treatment of DsRed ${ }_{\text {CAG10o Drosophila with }}$ L1P3V8 also suppressed retinal degeneration (Fig. 4d and e). These findings indicate that lipidation of P3V8 improved its cell penetration properties without affecting its inhibitory activity.

Lipidation improved P3V8 in vitro stability. To test whether lipidation could also improve the stability of P3V8, we compared the stabilities of P3V8 and L1P3V8 in rat plasma and brain homogenate via in vitro incubation to estimate their extent of degradation in plasma and brain tissues. The results shown in Table 2 indicate that the stability of L1P3V8 in both rat plasma and rat brain homogenate at $37^{\circ} \mathrm{C}$ was significantly improved in comparison to that of P3V8. At the concentration of $2000 \mathrm{ng} / \mathrm{mL}$, only $21 \%$ and $3 \%$ of P3V8 remained stable in plasma and brain homogenates, respectively, whereas nearly all L1P3V8 remained intact in plasma and around $45 \%$ of L1P3V8 could be detected in the brain homogenate after $1 \mathrm{hr}$ of incubation. When the incubation was extended to $3 \mathrm{hr}$, around $87 \%$ and $21 \%$ of L1P3V8 were still detectable in the plasma and brain homogenates, respectively, whereas P3V8 was almost completely degraded. Such improved stability of L1P3V8 was also observed in plasma when the experiments were repeated using $1000 \mathrm{ng} / \mathrm{mL}$ and $500 \mathrm{ng} / \mathrm{mL}$ of L1P3V8. Because the concentrations of both P3V8 and L1P3V8 after incubation at $500 \mathrm{ng} / \mathrm{mL}$ with brain homogenates were below the limit of quantitation (LOQ), no conclusion on comparison of their stabilities in brain homogenate could be drawn. Nonetheless, our results demonstrate that lipidation of P3V8 with palmitic acid significantly improved its stability in different biological matrices.

In vivo pharmacokinetic properties and brain uptake of P3V8 and L1P3V8. The plasma concentration versus time profiles of P3V8 and L1P3V8 after intravenous administration at $3 \mu \mathrm{mol} / \mathrm{kg}$ in Sprague Dawley (SD) rats were studied and compared (Fig. 5a and Table 3). Without lipidation, P3V8 was quickly eliminated in the plasma $10 \mathrm{~min}$ after administration and its half-life was too short to be determined. In contrast, L1P3V8 had a significantly longer half-life of $17 \mathrm{~min}$ (Table 3) and remained quantifiable at $190 \mathrm{nmol} / \mathrm{L}$ in the plasma $90 \mathrm{~min}$ after dosing (Fig. 5a). The maximum observed drug concentration $\left(\mathrm{C}_{\max }\right)$ and integrated time-concentration responses (area under the curve, AUC) of L1P3V8 were also significantly higher than that of P3V8 (Table 3), indicating better plasma stability after lipidation. The ability of P3V8 and L1P3V8 to be taken up by the brain was also analyzed after intravenous bolus injection. It was noticed that no P3V8 and $13 \mathrm{pmol} / \mathrm{g} \mathrm{L1P3V} 8$ was detected in the rat brain 20 min after administration (Fig. 5b), suggesting that intravenous administration might not be suitable for brain delivery of these peptides. These undesirable pharmacokinetic properties led us to explore an alternative route of delivery of these peptides to the brain. One of the options is intranasal administration. Intranasal delivery involves the externally exposed olfactory or trigeminal nerve systems and thus is the most direct method of noninvasive delivery method to the brain ${ }^{27}$. Both P3V8 and L1P3V8 were administered intranasally into SD rats at a dose of $3 \mu \mathrm{mol} / \mathrm{kg}$ with pretreatment of $0.5 \%$ mucoadhesive chitosan. The pharmacokinetic profiles obtained are significantly different from those obtained after intravenous administration (Fig. $5 \mathrm{c}$ and Table 3). It was noted that the plasma levels of the intranasally administered inhibitors were significantly lower than that from intravenous administrations. The concentration of P3V8 in plasma peaked at $15 \mathrm{~min}$ and diminished rapidly within $20 \mathrm{~min}$, whereas L1P3V8 concentration peaked at $18 \mathrm{~min}$ and remained stay around $9 \mathrm{nmol} / \mathrm{mL}$ at $90 \mathrm{~min}$. Similar to the observations from intravenous administration, both $\mathrm{C}_{\max }$ and AUC of L1P3V8 were significantly higher than those of P3V8 after intranasal administration, which clearly demonstrates again that lipidation of the inhibitor increased its systemic exposure. In addition, significantly higher concentrations of L1P3V8 (58 pmol/g) 
(a)

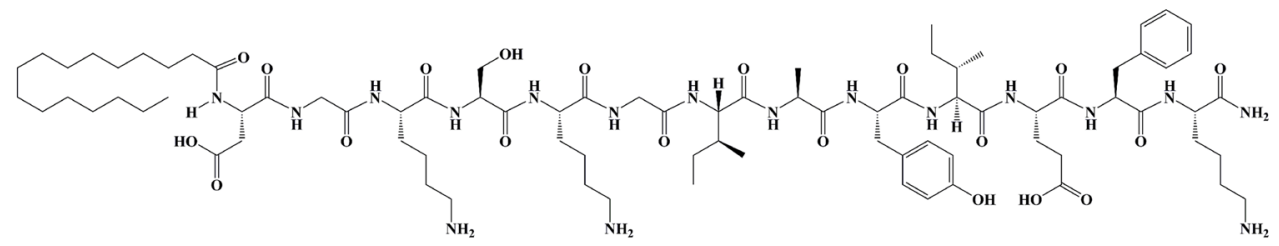

(b)

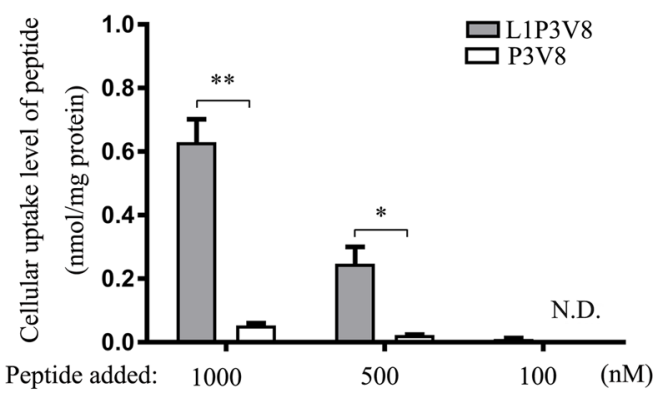

(c)

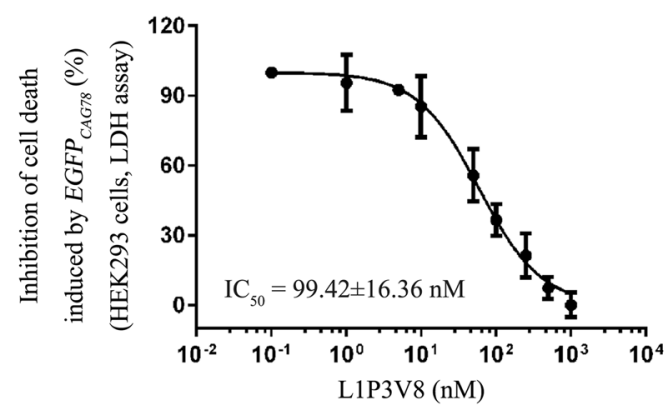

(d)

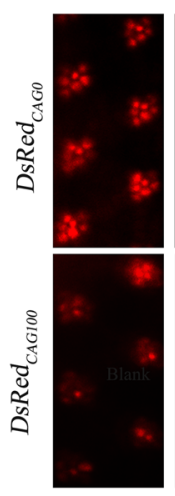

Blank

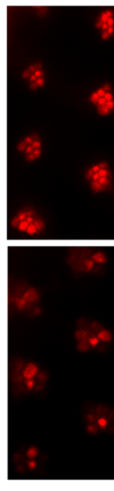

L1P3V8

$(0.01 \mu \mathrm{M})$

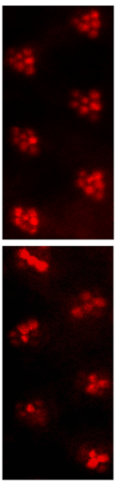

L1P3V8 $(0.1 \mu \mathrm{M})$

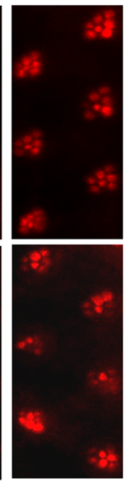

L1P3V8 $(1 \mu \mathrm{M})$
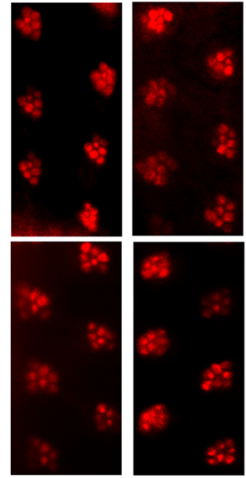

L1P3V8 $(10 \mu \mathrm{M})$

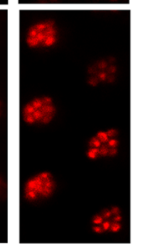

L1P3V8

$(50 \mu \mathrm{M})$

(e)

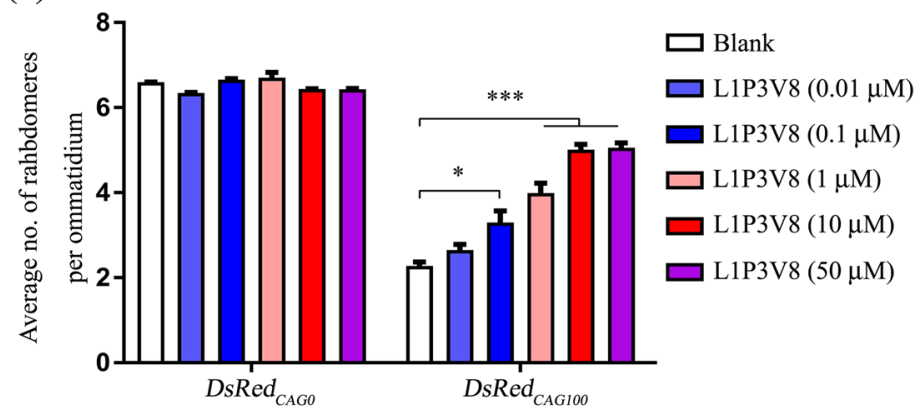

Figure 4. L1P3V8 effectively inhibits neurodegeneration induced by expanded CAG RNA in vitro and in vivo. (a) Chemical structure of L1P3V8. (b) Comparison of cellular uptake level of P3V8 and L1P3V8 in HEK293 cells. Cellular uptake level was measured $3 \mathrm{hr}$ after 100,500 or $1000 \mathrm{nM}$ treatment of respective peptide. The total amount of peptide in the cell lysate was normalized to total protein level in cell lysate. (c) Dose-dependent effect of synthetic L1P3V8 on the inhibition of cell death in $E G F P_{C A G 78}$ RNA-expressing HEK293 cells. Various amount of L1P3V8 were added into individual culture wells immediately after plasmid transfection. LDH cytotoxicity assay was performed. The $\mathrm{IC}_{50}$ value represents the concentration of peptides that reduced LDH enzyme activity by $50 \%$ when compared with the no peptide treatment control group. (c) Effect of L1P3V8 on suppressing DsRedCAG ${ }_{100}$ neurodegeneration in Drosophila. (d) Statistical analysis of panel (c). Pseudopupil assay was performed on 12 day-old adult flies. The flies were of genotypes $w ; g^{2} r$-GAL4 UAS-DsRed $d_{C A G o}$ o; $+/+$ and $w ; g m r-G A L 4 /+; U A S-D s R e d_{C A G 100} /+$. Data are expressed as mean \pm S.E.M. for at least 3 independent experiments. *Indicates $P<0.05$ and **indicates $P<0.01$. 


\begin{tabular}{|l|l|l|l|l|l|}
\hline & \multicolumn{4}{|l|}{ Percentage of remained (\%) } \\
\cline { 3 - 7 } & \multicolumn{4}{|l|}{ Incubation for $\mathbf{~ h r}$} & \multicolumn{2}{l|}{ Incubation for 3 hr } \\
\hline \multirow{4}{*}{ Plasma } & $\begin{array}{l}\text { Incubation Conc. } \\
(\mathrm{ng} / \mathrm{mL})\end{array}$ & P3V8 & L1P3V8 & P3V8 & L1P3V8 \\
\hline \multirow{3}{*}{ Brain homogenate } & 2000 & $20.7 \pm 3.3$ & $98.8 \pm 5.0^{* * *}$ & $<0.6^{*}$ & $86.9 \pm 5.5$ \\
\cline { 2 - 7 } & 1000 & $8.6 \pm 0.5$ & $98.7 \pm 3.9^{* * *}$ & $<1.3^{*}$ & $81.2 \pm 1.5$ \\
\cline { 2 - 7 } & 500 & $<2.5^{*}$ & $88.1 \pm 4.9$ & $\mathrm{~N} / \mathrm{A}$ & $73.8 \pm 5.7$ \\
\cline { 2 - 7 } & 2000 & $3.3 \pm 0.6$ & $45.0 \pm 3.5^{* * *}$ & $<0.6^{*}$ & $21.2 \pm 3.0$ \\
\cline { 2 - 7 } & 500 & $4.0 \pm 1.6$ & $22.8 \pm 1.2^{* * *}$ & $<1.3^{*}$ & $15.8 \pm 0.7$ \\
\hline
\end{tabular}

Table 2. Stability of P3V8 and L1P3V8 in different biological matrices after incubation at $37^{\circ} \mathrm{C}$. Data are presented as mean \pm S.E.M. for 5 independent experiments. ***Indicates $P<0.001$, significant difference compared with P3V8. "Indicates the concentration was below the lowest limit of quantification $(12.5 \mathrm{ng} / \mathrm{mL}$ for P3V8 and $100 \mathrm{ng} / \mathrm{mL}$ for L1P3V8). N/A indicates not applicable.

(a)

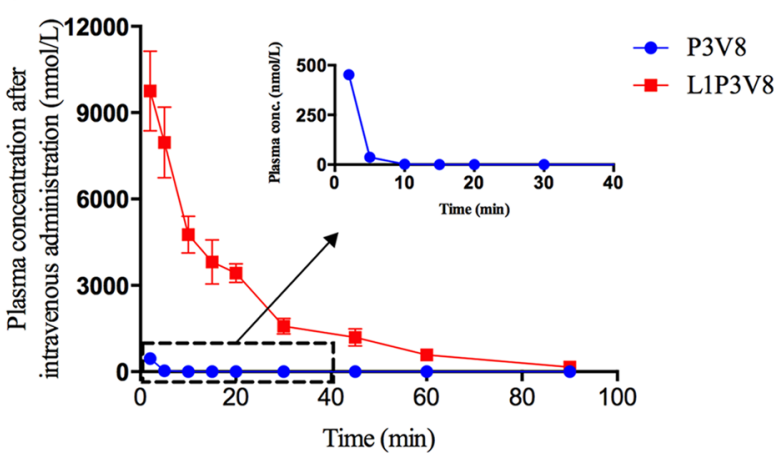

(c)

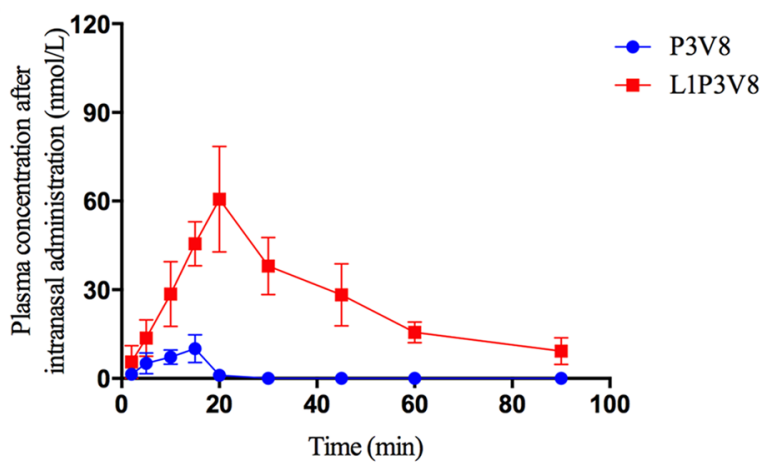

(b)

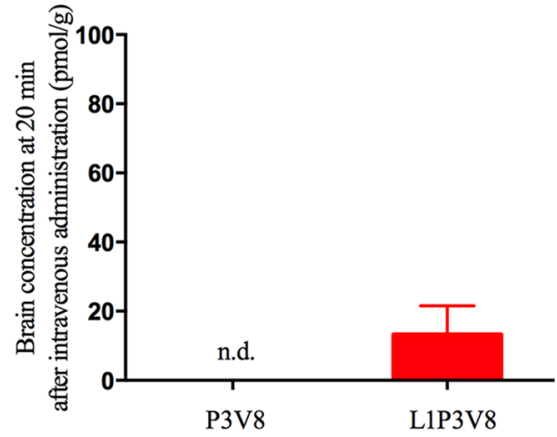

(d)

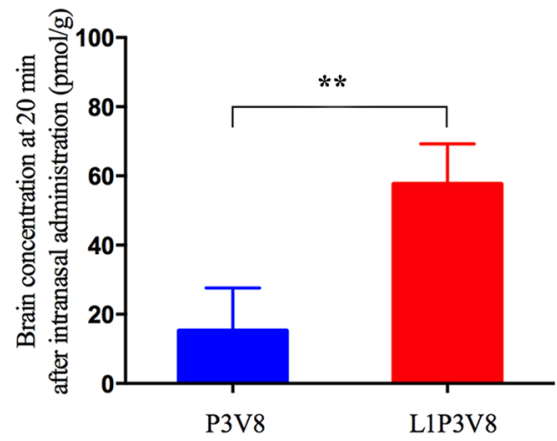

Figure 5. In vivo pharmacokinetic study and brain uptake of $3 \mu \mathrm{mol} / \mathrm{kg} \mathrm{P} 3 \mathrm{~V} 8$ or L1P3V 8 in rats. (a) Inhibitor plasma concentration-time profiles of $\mathrm{P} 3 \mathrm{~V} 8$ and L1P3V8 following intravenous administration. (b) Brain concentrations of P3V8 (n.d.: not detected) and L1P3V8 at 20 min after intravenous administration (c) Inhibitor plasma concentration-time profiles of inhibitors administered via the intranasal route after pre-treatment with $0.5 \%$ chitosan. (d) Brain concentrations of P3V8 and L1P3V8 at 20 min after intranasal administration. Data are presented as mean \pm S.E.M. for 6 independent experiments. **Indicates $P<0.01$.

and P3V8 (15 pmol/g) in the brain were achieved $20 \mathrm{~min}$ after intranasal dosing, as compared to those from intravenous administration, indicating better brain uptake via the intranasal route (Fig. $5 \mathrm{~d}$ ). Taken together, our findings support that the combined strategies of lipidation and intranasal administration significantly improve the pharmacokinetic properties and brain uptake of our peptide inhibitor.

\section{Discussion}

Despite our growing knowledge of the role of RNA transcripts in the pathological mechanisms of polyQ diseases, there is a lack of inhibitors that can counteract their neurotoxicity. On the basis that sequestration of NCL by expanded CAG RNA induces cytotoxicity, we recently developed a peptide inhibitor P3 that disrupts NCL-RNA 


\begin{tabular}{|l|l|l|l|l|}
\hline \multirow{2}{*}{} & \multicolumn{2}{|l|}{ Intravenous administration } & \multicolumn{2}{l|}{$\begin{array}{l}\text { Intranasal administration } \\
\text { (Pre-treated with 0.5\% chitosan) }\end{array}$} \\
\cline { 2 - 5 } & P3V8 & L1P3V8 & P3V8 & L1P3V8 \\
\hline $\mathrm{C}_{\max }(\mathrm{nmol} / \mathrm{L})$ & $452 \pm 22$ & $10394 \pm 1225^{* * *}$ & $12 \pm 2$ & $74 \pm 13^{* * *}$ \\
\hline $\mathrm{T}_{\max }(\min )$ & $2 \pm 0$ & $2 \pm 0$ & $15 \pm 4$ & $18 \pm 1$ \\
\hline $\mathrm{AUC}_{0-\text { last }}(\min * \mathrm{nmol} / \mathrm{L})$ & $1212 \pm 80$ & $179470 \pm 18874^{* * *}$ & $85 \pm 32$ & $2277 \pm 558^{* * *}$ \\
\hline $\mathrm{T}_{1 / 2}(\min )$ & $\mathrm{N} / \mathrm{A}$ & $17 \pm 4$ & N/A & $37 \pm 5$ \\
\hline
\end{tabular}

Table 3. Comparison of pharmacokinetic parameters of P3V8 and L1P3V8 after intravenous or intranasal administrations at $3 \mu \mathrm{mol} / \mathrm{kg}$. Data are presented as mean \pm S.E.M. for 6 independent experiments. ***Indicates $P<0.001$, significant difference compared with P3V8. N/A indicates the parameter is not applicable due to insufficient time points with detectable plasma concentrations in elimination phase.

interaction and consequently mitigates RNA toxicity in polyQ diseases. In this study, we determined the equilibrium dissociation constant $\mathrm{K}_{\mathrm{D}}$ of P3 using ITC and discovered that the binding of P3 to RNA is both enthalpically and entropically favored. Short peptides like the 13-mer P3 usually assume flexible conformations in an aqueous solution and therefore suffer entropic loss upon binding to their targets. The finding that P3 binds expanded RNA with a favorable $\mathrm{T} \Delta \mathrm{S}$ suggests that $\mathrm{P} 3$ may have undergone a conformation change upon binding to the RNA in solution.

When characterizing the effects of Ala substitutions of the pharmacophores of P3 on its interaction with expanded CAG RNA, we found that the basic Lys residues are more important than the aromatic residues in the interaction with expanded RNA. Substitution of any of the three Lys in P3 greatly reduced its binding affinity to RNA, indicating that electrostatic interactions play a dominant role in the affinity of $\mathrm{P} 3$. This is no surprise because CAG-repeat RNA duplex adopts an A' helical conformation that is intermediate to the A- and B-forms of nucleic acids and is highly electronegative on its surface and thus charge-complementary with the key pharmacophores of P3. As described above, the substitution of Lys at positions 3 and 5 by Arg remarkably improved the binding affinity of the peptide by nearly 10 -fold (Table 1, P3V5). This observation suggests that the higher $\mathrm{pKa}$ of arginine and its guanidinium group may have further strengthened the ionic interaction with the RNA. Surprisingly, when we further mutated Lys 13 to arginine, the binding affinity of the peptide was adversely reduced by nearly 3 -fold, indicating that the amine group of Lys13, but not the charge alone, is critical for the binding of P3 and RNA. Further research is needed to investigate whether the side chain amine of Lys13 is important for stabilizing the peptide for RNA recognition or for mediating the critical interaction with nucleic acid.

Previous studies have shown that the charge neutralization of the $\mathrm{N}$ - and C-termini of synthetic peptides by acetylation and amidation can improve their stabilities in cell cultures and serum, thus improving their biological activity. Based on these findings, we generated P3V8, which is capped by acetylation and amidation at the N-and C-termini, respectively, in an attempt to improve the biological activity of $\mathrm{P} 3$ and in hopes that the same strategy can be applied to other $\mathrm{P} 3$ derivatives. We observed that capping of both termini of $\mathrm{P} 3$ not only improved its binding affinity to expanded $C A G$ RNA $\left(\mathrm{K}_{\mathrm{D}}=0.33 \mu \mathrm{M}\right)$ but also significantly improved its potency both in vivo and in vitro. In a recent study of compounds that block Alzheimer's $A \beta$ channel activity, Flora and colleagues showed that capping of the amine and carboxyl groups of free histidine helps to improve the residue activity by preventing nonspecific interaction with other reactive residues in the target ${ }^{28}$. We speculate that the capping of P3, now termed P3V8, might have exerted a similar effect and prevented nonspecific interaction between the peptide and the RNA's negatively charged surface, thus improving the binding and efficacy of the peptide. Furthermore, the slight increase in $\mathrm{pI}$ of the peptide might also have contributed to its better affinity to the electrostatically negative surface of RNA (P3V8, pI = 10.02 vs. $\mathrm{P} 3, \mathrm{pI}=9.64$ ).

With the success of P3V8, we applied the same capping strategy to P3V5 to further improve its activity. However, as described above, the combination of Lys-to-Arg mutations of residues 3 and 5 and the capping of the peptide termini did not improve the peptide's binding affinity but instead reduced the $\mathrm{K}_{\mathrm{D}}$ to about $2.3 \mu \mathrm{M}$. We speculate that upon $\mathrm{N}$ - and C-termini modifications, the interactions of the arginines and RNA might have been altered and that P3V9 likely adopts a different binding mode than P3V5 or P3V8. Moreover, the lengths of the basic side chains at residues 3 and 5 also appear to play a determining role in the binding of the peptide, as either lengthening or shortening the basic side chains abolished the interaction between the inhibitors and expanded RNA, suggesting that the distances between the basic side chains and the RNA is critical and that only limited conformational flexibility is allowed after P3V8 binds to the RNA. Such a rigid binding mode of P3V8 is further supported by the observation that tandem repeats of the peptide failed to interact with the expanded RNA. Studies on the conformation and dynamics of P3V8 before and after RNA binding are needed to understand the mechanism of its specific inhibitory activity.

RNAs are becoming more recognized as attractive therapeutic targets because they fold into well-defined secondary and tertiary structures but exhibit a large variety of conformations, which can provide favorable opportunities for specific drug targeting. One interesting feature of the A' form of CAG RNA is the widened major groove caused by the non-canonical AA base pairs ${ }^{29}$. Such widening provides binding sites that are unique to CAG-repeat RNA, and their accessibility may offer opportunity to improve the potency and specificity of our inhibitor. Further structural information on the interaction between P3V8 and CAG RNA will be useful to provide insight into how to make use of such a unique feature. Nevertheless, the results of our study demonstrates that neutralization of the $\mathrm{N}$ - and C-termini by simple modifications like acetylation and amidation can have significant effects on the binding and inhibitory properties of peptidyl inhibitor against an RNA target. 
In the past few decades, several inhibitors targeting protein toxicity ${ }^{30-33}$ or CAG RNA toxicity ${ }^{21,34}$ in polyQ disease have been developed. Some even showed therapeutic potential ${ }^{30-33}$. In this study, we demonstrated for the first time a structural activity relationship (SAR) investigation of the peptidylic inhibitor, P3, toward CAG RNA toxicity in polyQ diseases. The SAR study led us to identify a more potent peptide derivative of P3, P3V8, which shows dramatically improved inhibitory efficacy against expanded RNA-mediated toxicity in vivo. However, many peptides have short half-life in vivo, typically in minutes, which raises concern whether P3V8 could be administered as a therapeutic agent. Previous studies have established that covalent anchoring of lipids to peptides promotes peptide binding to the fatty acid binding sites on albumin ${ }^{35}$. As albumin has a very long half-life, this 'docking' into albumin can significantly extend the functional half-life of peptides. Furthermore, we speculated that lipidation of a peptide could improve the ability to cross cell membranes and enter cells. We therefore lipidated P3V8 by N-acylation with palmitic acid. Stability studies of the lipidated peptide L1P3V8 in plasma and brain homogenates revealed that lipidation significantly enhanced the cellular uptake and in vivo stability of P3V8. Above all, the lipidation strategy notably improved the pharmacokinetic profile and brain uptake of L1P3V8 in rats when it was administered intranasally, conferring our inhibitor drug/lead-like properties. The ability of therapeutic agents to pass the blood-brain-barrier is one of the most critical requirements for treatment of neuronal diseases. Although the mechanism of brain uptake of L1P3V8 remains to be elucidated, our results illustrate that the combination of lipidation and intranasal administration may provide a new means to improve the brain uptake of therapeutic agents. In conclusion, our results provide proof of concept that lipidated peptidyl inhibitors that target RNA toxicity are a novel therapeutic option for polyQ diseases. Further modification and optimization on this lead-like L1P3V8 will be needed to prolong its half-life and uptake level in the brain.

\section{Methods}

Peptide modeling. Molecular modeling of P3V8 was carried out using the online PEP-FOLD 2.0 server $^{23}$. The sequence of the 13 amino acid peptide was submitted to the server and 100 simulations were performed using the default settings. The program returned the most representation conformations identified in terms of energy and population, and clustered them based on their sOPEP (Optimized Potential for Efficient structure Prediction) coarse grained energies. The representative model of the top-ranked cluster with the lowest sOPEP energy values was selected for this study.

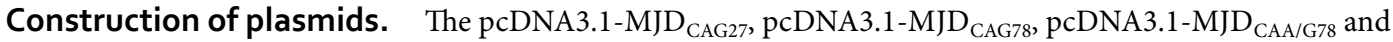
$\mathrm{pEGFP}_{\mathrm{CAG78}}$ constructs were reported previously ${ }^{7,13}$.

Synthesis of peptides and CAG RNAs. P3WT and P3 mutant (MT) peptides were purchased from GenScript USA Inc. All other peptide variants were prepared by Fmoc solid-phase peptide synthesis on automated peptide synthesizers, Biotage Syro Wave and Biotage SP Wave instruments, and assembled on a $0.1 \mathrm{mmol}$ scale, unless noted otherwise. Peptide syntheses were carried out on a TentaGel S Rink Amide resin ( $0.22 \mathrm{mmol} / \mathrm{g})$. Amino acids had Fmoc protection of $\mathrm{N} \alpha$-amino groups; side-chain protecting groups were tert-butyl (Tyr, Glu, Asp), 2,2,4,6,7-pentamethyl-dihydrobenzofuran-5-sulfonyl (Pbf, for Arg and hArg), and tert-butyloxycarbonyl (Boc, for Lys, Orn and Dap). Amino acids, NMP, DMF and piperidine were supplied by Iris Biotech (Germany). Acetonitrile, formic acid, triethylsilane (TES), trifluoroacetic acid (TFA) acetic anhydride, and dichloromethane (DCM) were from Sigma-Aldrich (Denmark). All chemicals were used as received and without further purification.

Analytical HPLC was performed with a Dionex Ultimate 3000 instrument on a Phenomenex Germini-NX C18 column $(3 \mu \mathrm{m}, 50 \times 4.6 \mathrm{~mm})$, column oven thermostated to $42^{\circ} \mathrm{C}$, and a linear gradient flow of $\mathrm{CH}_{3} \mathrm{CN}-\mathrm{H}_{2} \mathrm{O}$ ( $0.1 \%$ formic acid), connected to an ESI-MS (MSO Plus Mass Spectrometer, Dionex). Purification of the peptide was performed on a preparative Dionex Ultimate 3000 HPLC with a C18 column Phenomenex Gemini Axia $(5 \mu \mathrm{m}, 100 \times 21.2 \mathrm{~mm}, 110 \AA$ A $)$. Unless otherwise stated $\mathrm{CH}_{3} \mathrm{CN}-\mathrm{H}_{2} \mathrm{O}(0.1 \% \mathrm{TFA}$ or $0.1 \%$ formic acid $)$ was used as eluent with a flow of $15 \mathrm{~mL} / \mathrm{min}$. Gradient elution for $0-5 \mathrm{~min}$ was $5 \%$, then to $55 \%$ for $5-32 \mathrm{~min}$.

All standard Fmoc amino acids were coupled in DMF with 5.2 equivalents of amino acids and HOAt, with 5 equivalents of HBTU and 9.4 equivalents DIEA. The coupling time was $60 \mathrm{~min}$ at room temperature. All non-standard amino acids, as well as palmitic acid, were coupled using 2 equivalents of amino acids and HOAt, 1.9 equivalents of HBTU and 3.6 equivalents DIEA. Coupling times were $10 \mathrm{~min}$ at $75^{\circ} \mathrm{C}$. $\mathrm{N}$-terminal fatty acid was introduced using the same conditions as for the coupling of standard amino acids.

In the synthesis of peptides P3V7 to P3V21, the first 10 couplings used a coupling time of $60 \mathrm{~min}$ at $25^{\circ} \mathrm{C}$ with NMP and washings in-between couplings. Deprotections were performed by treatment with piperidine-DMF (2:3) for $3 \mathrm{~min}$, followed by piperidine-DMF (1:4) for $15 \mathrm{~min}$. After each coupling and deprotection, a washing procedure with NMP $(3 \mathrm{x})$, DCM $(1 \mathrm{x})$, then NMP $(3 \mathrm{x})$ was performed. From the 10 th coupling onwards, the coupling time was increased to $2 \times 120 \mathrm{~min}$ and an extra deprotection step ( $15 \mathrm{~min}$ ) with piperidine-DMF (1:4) was added. The N-terminal acetylation was achieved with acetic anhydride in DMF (1:4) for $2 \times 15$ min. After completion of peptide chain assembly, the resin was washed 6 times with DCM. All the peptides were released and deprotected by treatment with a cocktail of trifluoroacetic acid (TFA), triethylsilane (TES) and $\mathrm{H}_{2} \mathrm{O}$ (95:2:3 or 95:2.5:2.5) for $2 \mathrm{hr}$. The TFA solutions were concentrated under a flow of nitrogen and the compounds were precipitated with diethylether to yield the crude products. All peptides were purified by RP-HPLC.

The sequences of peptides are listed in Table 1, Supplementary Tables S1 and S2. The purity of peptides used in cell experiments and in vitro binding was over $90 \%$. Desalted peptides were used in Drosophila feeding assays. All RNAs were synthesized using the MEGAscript ${ }^{\circledR}$ kit (Ambion) as previously described ${ }^{13}$, and the $M J D_{\text {CAG27, }}$, $M J D_{C A G 78}$ and $M J D_{C A A / G 78}$ RNAs were transcribed from linearized $p c D N A 3.1-M J D_{C A G}$ constructs $^{36}$. 
Isothermal titration calorimetry binding assay. Experiments were carried out using a MicroCal iTC200 isothermal titration calorimeter (GE Healthcare) at $25^{\circ} \mathrm{C}$. Data were analyzed using the Origin ${ }^{\circledR}$ scientific plotting software version 7 (Microcal Software Inc.). All RNAs and peptides were dissolved in binding buffer (20 mM MOPS, $\mathrm{pH} 7.0 ; 300 \mathrm{mM} \mathrm{NaCl}$ ) and $0.7 \mathrm{mM}$ of peptide was titrated into $0.5 \mu \mathrm{M}$ of RNA for each experiment. The concentration of RNA was estimated with appropriate extinction coefficients at $260 \mathrm{~nm}$ on a Nanodrop 2000 (Thermo Scientific). A reference power of $8 \mu \mathrm{cal} / \mathrm{s}$ was used with an initial $0.5 \mu \mathrm{l}$ of injection of peptide followed by $2 \mu \mathrm{l}$ for all subsequent titrations points with a $60 \mathrm{sec}$ initial equilibrium delay and $150 \mathrm{sec}$ pause between injections. The samples were stirred at a speed of $1000 \mathrm{rpm}$ throughout the experiment. The thermal titration data were fitted to the 'one binding site model' to determine the dissociation constant $\left(\mathrm{K}_{\mathrm{D}}\right)$. Each experiment was repeated at least 3 times with consistent results obtained.

Cell culture, plasmid transfection and peptide transfection. HEK 293 cells were cultured at $37^{\circ} \mathrm{C}$ with $5 \% \mathrm{CO}_{2}$ in DMEM supplemented with $10 \% \mathrm{FBS}$ and $1 \%$ penicillin-streptomycin. Primary rat cortical neurons were isolated and cultured as previously described ${ }^{37}$. Transient transfection of HEK293 cells was performed using Lipofectamine 2000 (Life Technologies). P3V8 were delivered to HEK293 cells using the DeliverX (DX) Peptide Transfection Kit (Affymetrix) $4 \mathrm{hr}$ after DNA transfection. At least two batches of independently synthesized peptides were used in the experiments.

Lactate dehydrogenase (LDH) cytotoxicity assay and IC ${ }_{50}$ determination. To detect the effect of P3V8 and lipidated P3V8 (L1P3V8) on inhibiting cell death in EGFP ${ }_{C A G 78}$ RNA-expressing HEK293 cells, a LDH assay was employed. HEK 293 cells were seeded on a 24 -well plate at a density of $0.5 \times 10^{5}$, and pEGFP${ }_{C A G 78}$ DNA construct was used to transfect the cells. For P3V8 treatment, different concentrations of P3V8 as indicated in the figure were transfected by DeliverX transfectant $4 \mathrm{hr}$ after DNA transfection. For L1P3V8 treatment, different concentrations of L1P3V8 were added into individual wells immediately after DNA transfection. Seventy-two hours after treatment, LDH enzyme activity in the cell culture medium was measured as described before. Experimental groups were normalized to the untransfected control. After normalization, data were analyzed using the dose response-inhibition curve (nonlinear regression-variable slope) to determine the $\mathrm{IC}_{50}$ value (Prism6 software, GraphPad Software, Inc.). Each experiment was repeated at least 3 times.

Drosophila genetics, peptide feeding and assays. Flies were raised at $21.5^{\circ} \mathrm{C}$ on cornmeal medium supplemented with dry yeast. Fly lines bearing UAS-DsRed ${ }_{C A G O}$ and $U A S-D s R e d_{C A G 100}$ were kind gifts of Professor Nancy Bonini (University of Pennsylvania, USA). The gmr-GAL4 fly line was obtained from Bloomington Drosophila Stock Center. For pseudopupil assay, third instar larvae were fed with various amount of respective peptides dissolved in $2 \%$ sucrose solution for $2 \mathrm{hr}$ and then continued to culture in standard fly food at $21.5^{\circ} \mathrm{C}^{38}$. Pseudopupil assay was performed on 12 day-old adult flies as mentioned previously ${ }^{39}$. Images were captured by SPOT Insight CCD camera controlled by the SPOT Advanced software (Diagnostic instruments Inc.). Image processing was performed using the Adobe Photoshop CS software (Adobe). Each experiment was repeated at least 3 times ( $\mathrm{n}=10$ fly heads), and consistent results were obtained. For viability test of wild-type flies from egg to adult stage, eggs born within $5 \mathrm{hr}$ were collected and cultured in fly food containing 10 or $50 \mu \mathrm{M}$ of respective peptides at $21.5^{\circ} \mathrm{C}$. Viability from egg-to-adult was calculated as the number of adult flies collected divided by the number of eggs examined. Each experiment was repeated for three times (at least 130 eggs were examined in each group). Two batches of independently synthesized peptides were used in the experiments.

RNA extraction, reverse transcription-PCR and real-time PCR. RNA was extracted from cells or ten 12 day-old adult fly heads by Trizol reagent (Life Technologies), and $1 \mu \mathrm{g}$ of purified RNA was then used for reverse-transcription using the ImPromII ${ }^{\mathrm{TM}}$ Reverse Transcription System (Promega). Random hexamer (Roche) was used as primers in reverse transcription. Taqman gene expression assays were performed on an ABI 7500 Real-time PCR system and data were analyzed as previously described ${ }^{13}$. The following probes were used: pre- $45 \mathrm{~s}$ $r R N A$ (Assay ID: AILJIZM), pre-rRNA (Assay ID: AIMSG5U), Drosophila GAPDH (Assay ID: Dm01841186) and human actin (Assay ID: Hs99999903_m1). Each experiment was repeated at least 3 times.

In vitro stability studies in rat plasma and brain homogenate. Sprague-Dawley (SD) rats (male, $180-200 \mathrm{~g}$ ) were supplied by the Laboratory Animal Services Centre at The Chinese University of Hong Kong. All animal studies were conducted under the approval of the Animal Ethics Committee of The Chinese University of Hong Kong, and were performed in accordance with relevant guidelines and regulations. Blank rat brain homogenate was prepared by ultrasonic probe homogenization (Micoson XL-2000, Misonix, Framingdale, NY, USA) of brains collected from the control rats. Blank rat plasma was prepared by centrifugation ( $8000 \mathrm{rcf}$ for $3.5 \mathrm{~min}$ ) of blood collected from control rats. For the stability test, $2000 \mathrm{ng} / \mathrm{mL}$ and $500 \mathrm{ng} / \mathrm{mL}$ of P3V8 or L1P3V8 was spiked into the blank rat plasma or brain homogenate and vortexed. The mixtures were incubated at $37^{\circ} \mathrm{C}$ with $100 \mathrm{rpm}$ in a water bath for 1 or $3 \mathrm{hr}$. The incubation was terminated by addition twice the volume of acetonitrile and centrifugation at $13000 \mathrm{rcf}$ for $10 \mathrm{~min}$. The supernatant was collected for LC/MS/MS analysis.

Cellular uptake studies in HEK293 cells. HEK293 cells were seeded on a 6-well plate at a density of $6 \times 10^{5}$ and cultured overnight at $37^{\circ} \mathrm{C}$ with $5 \% \mathrm{CO}_{2}$ in DMEM supplemented with $10 \%$ FBS and $1 \%$ penicillin-streptomycin. Cells were then treated with 100,500 or $1000 \mathrm{nM}$ of respective peptide at $37^{\circ} \mathrm{C}$ for $3 \mathrm{hr}$. After treatment, the cells were washed with ice-cold PBS and then lysed by $2 \%$ SDS solution. Aliquot $(100 \mu l)$ of the cell lysate was added with $200 \mu \mathrm{l}$ acetonitrile and centrifuged at $13000 \mathrm{rcf}$ for $10 \mathrm{~min}$ to precipitate the proteins. The collected supernatant was subjected to LC/MS analysis. The protein concentration of the cell lysate was measured using a bicinchoninic acid protein assay kit following Sigma’s protocol. 
Plasma pharmacokinetic and brain uptake studies in SD rat. SD rats (180-200 g) were anesthetized with an intraperitoneal injection of ketamine $(60 \mathrm{mg} / \mathrm{kg})$ and xylazine $(6 \mathrm{mg} / \mathrm{kg})$ and received a minor surgery of cannulation with a polythene tube $(0.4 \mathrm{~mm}$ i.d., $0.8 \mathrm{~mm}$ o.d., Harvard Apparatus, Holliston, MA, USA) in the left jugular vein. The rats received an overnight recovery with free access to food and water. In the following day, rats were administered P3V8 or L1P3V8 $(3 \mu \mathrm{mol} / \mathrm{kg})$ via intravenous or intranasal routes. For intravenous administration, appropriate volume of P3V8 or L1P3V8 $(3 \mu \mathrm{mol} / \mathrm{mL}$, dissolved in water) was injected to the rats via the cannula. For intranasal administration, the rats were temporarily anesthetized by inhalation of carbon dioxide, and was administrated with appropriate volume of P3V8 or L1P3V8 $(30 \mu \mathrm{mol} / \mathrm{mL}$, dissolved in water with $5 \%$ PEG400) in both nostrils by a micropipette. Chitosan solution $(0.5 \% \mathrm{w} / \mathrm{v}, \mathrm{pH} 6.5,20 \mu \mathrm{L})$ was pre-treated to rats intranasally $5 \mathrm{~min}$ before the P3V8 and L1P3V8 was administrated via intranasal routes. For the pharmacokinetic study, after the drug administration, blood samples were collected from the catheter at appropriate time intervals $(2,5,10,15,20,30,45,60$, and $90 \mathrm{~min})$. After each collection, $0.2 \mathrm{~mL}$ of saline containing $25 \mathrm{IU}$ heparin was injected to compensate for the blood loss. Plasma was collected after centrifugation at $8000 \mathrm{rcf}$ for $3.5 \mathrm{~min}$ and stored at $-80^{\circ} \mathrm{C}$ until analysis. For brain uptake study, at $20 \mathrm{~min}$, the rat was anesthetized and perfused by $500 \mathrm{~mL}$ saline, and the whole brain was collected. The brain was wiped by tissue paper to remove excess water, meninges and blood vessels followed by storage at $-80^{\circ} \mathrm{C}$ until analysis.

Sample preparation for LC/MS/MS. Aliquot of plasma sample $(80 \mu \mathrm{L})$ was mixed with $160 \mu \mathrm{L}$ acetonitrile. The mixture was vortexed for $1 \mathrm{~min}$ and followed by centrifugation at $13000 \mathrm{rcf}$ for $10 \mathrm{~min}$. The supernatant was collect and subjected to LC/MS/MS analysis.

To prepare brain homogenate, the whole brain of each rat was minced. Saline $(2 \mathrm{~mL} / \mathrm{g}$ brain) was added followed by ultrasonic probe homogenization on ice. For analysis of P3V8, aliquot of brain homogenate $(100 \mu \mathrm{L})$ was mixed with $200 \mu \mathrm{L}$ acetonitrile. The mixture was vortexed for $1 \mathrm{~min}$ and followed by centrifugation at 13000 rcf for 10 min to collect the supernatant. For analysis of L1P3V8, aliquot of brain homogenate $(650 \mu \mathrm{L})$ was centrifuged at $6000 \mathrm{rcf}$ for $10 \mathrm{~min}$. After the supernatant was collected, $400 \mu \mathrm{L}$ saline was added to re-suspend the pellet. The mixture was again vortexed for $5 \mathrm{~min}$ and centrifuged at $6000 \mathrm{rcf}$ for $10 \mathrm{~min}$. The supernatant collected was loaded to a preconditioned Oasis ${ }^{\circledR}$ HLB cartridges (Waters, MA, USA). After washed with $1 \mathrm{~mL}$ of $10 \%$ acetonitrile in water, the analyte was eluted with $0.25 \mathrm{~mL} 95 \%$ acetonitrile in water.

LC/MS/MS analysis. Agilent 6430 Triple Quadrupole LC/MS/MS system (Agilent Technologies, CA, USA) was employed for the analysis. For analysis of P3V8, chromatographic separation was achieved on a SunFire C8 Column $(250 \mathrm{~mm} \times 4.6 \mathrm{~mm}, 5 \mu \mathrm{m})$. The mobile phase of water containing $0.2 \%$ formic acid (A) and acetonitrile (B) was used with a gradient elution $(0-5 \mathrm{~min}, 20-70 \% \mathrm{~B})$. The flow rate was $0.8 \mathrm{~mL} / \mathrm{min}$. Multiple reactions monitoring (MRM) with fragmentation transition of 500 to 129 in positive ion mode was employed for quantization of P3V8. For analysis of L1P3V8, Alltima Amino Alltech Column $(250 \mathrm{~mm} \times 4.6 \mathrm{~mm}, 5 \mu \mathrm{m})$ was used for separation. Mobile phase of water (A) and acetonitrile (B) was used. The gradient elution for plasma samples was 0-4 min, 30-95\% B, and for brain samples was 0-9 min, $10-95 \%$ B. The flow rate was $0.8 \mathrm{~mL} / \mathrm{min}$. MRM transition of 565 to 88 in positive ion mode was used for quantization of L1P3V8.

Data analyses. Plasma concentration verse time profiles were analyzed by WinNonlin (Pharsight Corporation, Mountain View, CA, USA, Version 2.1) to obtain the pharmacokinetics parameters. Other data were analyzed by one-way ANOVA followed by post hoc Tukey test or unpaired t-test. "*”, “**”, "***” and “****” represent $P<0.05, P<0.01, P<0.001$ and $P<0.0001$ respectively, which are considered statistically significant.

\section{References}

1. Orr, H. T. \& Zoghbi, H. Y. Trinucleotide repeat disorders. Annu. Rev. Neurosci. 30, 575-621 (2007).

2. Sakahira, H., Breuer, P., Hayer-Hartl, M. K. \& Hartl, F. U. Molecular chaperones as modulators of polyglutamine protein aggregation and toxicity. Proc. Natl. Acad. Sci. USA 99(Suppl 4), 16412-16418 (2002).

3. Takahashi, T., Katada, S. \& Onodera, O. Polyglutamine diseases: where does toxicity come from? what is toxicity? where are we going? J. Mol. Cell. Biol. 2, 180-191 (2010).

4. Michalik, A. \& Van Broeckhoven, C. Pathogenesis of polyglutamine disorders: aggregation revisited. Hum. Mol. Genet. 12(Spec No. 2), R173-86 (2003)

5. Fiszer, A. \& Krzyzosiak, W. J. RNA toxicity in polyglutamine disorders: concepts, models, and progress of research. J. Mol. Med. (Berl) 91, 683-691 (2013).

6. Fiszer, A. \& Krzyzosiak, W. J. Oligonucleotide-based strategies to combat polyglutamine diseases. Nucleic Acids Res. 42, 6787-6810 (2014).

7. Li, L. B., Yu, Z., Teng, X. \& Bonini, N. M. RNA toxicity is a component of ataxin-3 degeneration in Drosophila. Nature 453, 1107-1111 (2008).

8. Marti, E. RNA toxicity induced by expanded CAG repeats in Huntington's disease. Brain Pathol. 26, 779-786 (2016).

9. de Mezer, M., Wojciechowska, M., Napierala, M., Sobczak, K. \& Krzyzosiak, W. J. Mutant CAG repeats of Huntingtin transcript fold into hairpins, form nuclear foci and are targets for RNA interference. Nucleic Acids Res. 39, 3852-3863 (2011).

10. Mykowska, A., Sobczak, K., Wojciechowska, M., Kozlowski, P. \& Krzyzosiak, W. J. CAG repeats mimic CUG repeats in the misregulation of alternative splicing. Nucleic Acids Res. 39, 8938-8951 (2011).

11. Krol, J. et al. Ribonuclease dicer cleaves triplet repeat hairpins into shorter repeats that silence specific targets. Mol. Cell 25, 575-586 (2007).

12. Banez-Coronel, M. et al. A pathogenic mechanism in Huntington's disease involves small CAG-repeated RNAs with neurotoxic activity. PLoS Genet. 8, e1002481 (2012).

13. Tsoi, H., Lau, T. C., Tsang, S. Y., Lau, K. F. \& Chan, H. Y. CAG expansion induces nucleolar stress in polyglutamine diseases. Proc. Natl. Acad. Sci. USA 109, 13428-13433 (2012).

14. Tsoi, H. \& Chan, H. Y. Expression of expanded CAG transcripts triggers nucleolar stress in Huntington's disease. Cerebellum 12, 310-312 (2013)

15. James, A., Wang, Y., Raje, H., Rosby, R. \& DiMario, P. Nucleolar stress with and without p53. Nucleus 5, 402-426 (2014).

16. Wang, D. B., Kinoshita, C., Kinoshita, Y. \& Morrison, R. S. P53 and Mitochondrial Function in Neurons. Biochim. Biophys. Acta 1842, 1186-1197 (2014).

17. Zhang, Y. \& Lu, H. Signaling to p53: ribosomal proteins find their way. Cancer. Cell. 16, 369-377 (2009). 
18. Rickards, B., Flint, S. J., Cole, M. D. \& LeRoy, G. Nucleolin is required for RNA polymerase I transcription in vivo. Mol. Cell. Biol. 27, 937-948 (2007).

19. Ginisty, H., Amalric, F. \& Bouvet, P. Nucleolin functions in the first step of ribosomal RNA processing. EMBO J. 17, 1476-1486 (1998).

20. Bouvet, P., Diaz, J. J., Kindbeiter, K., Madjar, J. J. \& Amalric, F. Nucleolin interacts with several ribosomal proteins through its RGG domain. J. Biol. Chem. 273, 19025-19029 (1998).

21. Zhang, Q. et al. Assessing a peptidylic inhibitor-based therapeutic approach that simultaneously suppresses polyglutamine RNAand protein-mediated toxicities in patient cells and Drosophila. Dis. Model. Mech. 9, 321-334 (2016).

22. Fujiwara, Y. et al. Structure and function of the N-terminal nucleolin binding domain of nuclear valosin-containing protein-like 2 (NVL2) harboring a nucleolar localization signal. J. Biol. Chem. 286, 21732-21741 (2011).

23. Shen, Y., Maupetit, J., Derreumaux, P. \& Tuffery, P. Improved PEP-FOLD Approach for Peptide and Miniprotein Structure Prediction. J. Chem. Theory Comput. 10, 4745-4758, http://bioserv.rpbs.univ-paris-diderot.fr/services/PEP-FOLD/ (2014).

24. Knudsen, L. B. et al. Potent derivatives of glucagon-like peptide-1 with pharmacokinetic properties suitable for once daily administration. J. Med. Chem. 43, 1664-1669 (2000).

25. Madsen, K. et al. Structure-activity and protraction relationship of long-acting glucagon-like peptide-1 derivatives: importance of fatty acid length, polarity, and bulkiness. J. Med. Chem. 50, 6126-6132 (2007).

26. Oh, D. et al. Enhanced cellular uptake of short polyarginine peptides through fatty acylation and cyclization. Mol. Pharm. 11, 2845-2854 (2014).

27. Mittal, D. et al. Insights into direct nose to brain delivery: current status and future perspective. Drug Deliv. 21, 75-86 (2014).

28. Arispe, N., Diaz, J. C. \& Flora, M. Efficiency of histidine-associating compounds for blocking the alzheimer's Abeta channel activity and cytotoxicity. Biophys. J. 95, 4879-4889 (2008).

29. Tawani, A. \& Kumar, A. Structural Insights Reveal the Dynamics of the Repeating r(CAG) Transcript Found in Huntington's Disease (HD) and Spinocerebellar Ataxias (SCAs). PLoS One 10, e0131788 (2015).

30. Popiel, H. A. et al. The Aggregation Inhibitor Peptide QBP1 as a Therapeutic Molecule for the Polyglutamine Neurodegenerative Diseases. J. Amino Acids 2011, 265084 (2011).

31. Mishra, R. et al. Inhibiting the nucleation of amyloid structure in a huntingtin fragment by targeting alpha-helix-rich oligomeric intermediates. J. Mol. Biol. 415, 900-917 (2012).

32. Kazantsev, A. et al. A bivalent Huntingtin binding peptide suppresses polyglutamine aggregation and pathogenesis in Drosophila. Nat. Genet. 30, 367-376 (2002).

33. Arribat, Y. et al. A huntingtin peptide inhibits polyQ-huntingtin associated defects. PLoS One 8, e68775 (2013).

34. Kumar, A. et al. Chemical correction of pre-mRNA splicing defects associated with sequestration of muscleblind-like 1 protein by expanded r(CAG)-containing transcripts. ACS Chem. Biol. 7, 496-505 (2012).

35. van Witteloostuijn, S. B., Pedersen, S. L. \& Jensen, K. J. Half-Life Extension of Biopharmaceuticals using Chemical Methods: Alternatives to PEGylation. ChemMedChem 11, 2474-2495 (2016).

36. Tsoi, H., Lau, C. K., Lau, K. F. \& Chan, H. Y. Perturbation of U2AF65/NXF1-mediated RNA nuclear export enhances RNA toxicity in polyQ diseases. Hum. Mol. Genet. 20, 3787-3797 (2011).

37. Lau, K. F. et al. Dexras1 interacts with FE65 to regulate FE65-amyloid precursor protein-dependent transcription. J. Biol. Chem. 283, 34728-34737 (2008).

38. Chau, K. W., Chan, W. Y., Shaw, P. C. \& Chan, H. Y. Biochemical investigation of Tau protein phosphorylation status and its solubility properties in Drosophila. Biochem. Biophys. Res. Commun. 346, 150-159 (2006).

39. Wong, S. L., Chan, W. M. \& Chan, H. Y. Sodium dodecyl sulfate-insoluble oligomers are involved in polyglutamine degeneration. FASEB J. 22, 3348-3357 (2008).

\section{Acknowledgements}

This work was supported by the ANR/RGC Joint Research Scheme (A-CUHK401/14) and Collaborative Research Fund (CUHK1/CRF/13G) of the Hong Kong Research Grants Council; CUHK Lui Che Woo Institute of Innovative Medicine BRAIN Initiative (8303404); CUHK Group Research Scheme (3110102); CUHK Technology and Business Development Fund (TBF16SCI008); CUHK Vice-Chancellor's One-Off Discretionary Fund (VCF2014011); CUHK One-off Funding for Joint Lab/Research Collaboration (3132980); CUHK Gerald Choa Neuroscience Centre (7105306); and donations from Chow Tai Fook Charity Foundation (6903898) and Hong Kong Spinocerebellar Ataxia Association (6903291).

\section{Author Contributions}

Q.Z., H.Y.E.C., and J.C.K.N. conceived the study, analyzed the data and wrote the paper. Q.Z., Y.A., S.H.P., and Y.M. performed assays to analyze the inhibitory activities of peptides in vitro and in vivo. K.K.S., C.S.M., J.T.B. and K.J.J. designed, synthesized and purified the peptides. M.Y., Q.Z., and Z.Z. performed the in vitro stability and cell uptake, in vivo pharmacokinetics and sample analyses by LC/MS/MS. K.J.J., Z.Z., H.Y.E.C., and J.C.K.N. designed the peptides and experiments, and supervised the study. All authors contributed to discussions and reviewed the manuscript.

\section{Additional Information}

Supplementary information accompanies this paper at doi:10.1038/s41598-017-11695-y

Competing Interests: The authors declare that they have no competing interests.

Publisher's note: Springer Nature remains neutral with regard to jurisdictional claims in published maps and institutional affiliations.

Open Access This article is licensed under a Creative Commons Attribution 4.0 International License, which permits use, sharing, adaptation, distribution and reproduction in any medium or format, as long as you give appropriate credit to the original author(s) and the source, provide a link to the Creative Commons license, and indicate if changes were made. The images or other third party material in this article are included in the article's Creative Commons license, unless indicated otherwise in a credit line to the material. If material is not included in the article's Creative Commons license and your intended use is not permitted by statutory regulation or exceeds the permitted use, you will need to obtain permission directly from the copyright holder. To view a copy of this license, visit http://creativecommons.org/licenses/by/4.0/.

(C) The Author(s) 2017 